\title{
ECOLOGY
}

\section{Global warming and amphibian losses}

\author{
Arising from: J. A. Pounds et al. Nature 439, 161-167 (2006)
}

Is global warming contributing to amphibian declines and extinctions by promoting outbreaks of the chytrid fungus Batrachochytrium dendrobatidis? Analysing patterns from the American tropics, Pounds et al. ${ }^{1}$ envisage a process in which a single warm year triggers die-offs in a particular area (for instance, 1987 in the case of Monteverde, Costa Rica). However, we show here that populations of two frog species in the Australian tropics experienced increasing developmental instability, which is evidence of stress ${ }^{2-4}$, at least two years before they showed chytridrelated declines. Because the working model of Pounds et al. is incomplete, their test of the climate-linked epidemic hypothesis could be inconclusive.

Biotic or abiotic agents may cause stress. During amphibian growth and development, disease or physical stressors can increase the asymmetry of limb lengths ${ }^{3,4}$. Pounds et al. propose a mechanism for chytrid outbreaks, in which global warming favours the pathogen directly by shifting microscale temperatures towards its optimum. Unusual climatic conditions, however, may also stress amphibians ${ }^{5}$, potentially altering development and raising susceptibility to chytridiomycosis, as well as other diseases ${ }^{6}$. During an epidemic in New South Wales, Australia, in 1999, the chytrid was found in only seven of 32 moribund frogs (Limnodynastes tasmaniensis) ${ }^{7}$.

To investigate stress, we analysed limb asymmetries in populations near Paluma, in northern Queensland, Australia, just before their decline, and in non-declining 'control' populations of the same species. We measured limb elements of 164 adult males, including 112 Litoria nannotis (38 'control' and 74 'predecline') and 52 L. genimaculata (23 'control' and 29 'pre-decline'). The frogs were obtained during 30 samplings at different times ( $12^{\text {'con- }}$ trol', Fig. 1a; and 18 'pre-decline', Fig. 1b).

At Paluma between April and September 1991, L. nannotis collapsed and disappeared; L. genimaculata declined within 3 months afterwards but later recovered ${ }^{8}$. The controls, from 12 tropical wet forest sites, were obtained during nine years that preceded the die-offs at Paluma by an average of 16 years.

Using a blind protocol ${ }^{9}$, we measured every frog three times. We then examined asymmetry in relation to body size, and, using analysis of variance, partitioned the variation representing the different kinds of asymmetryand measurement error ${ }^{2,9}$. To compare samples, we examined the total unsigned asymmetry per individual (the difference between the left and right forelimbs, plus the corresponding value for the hindlimbs).
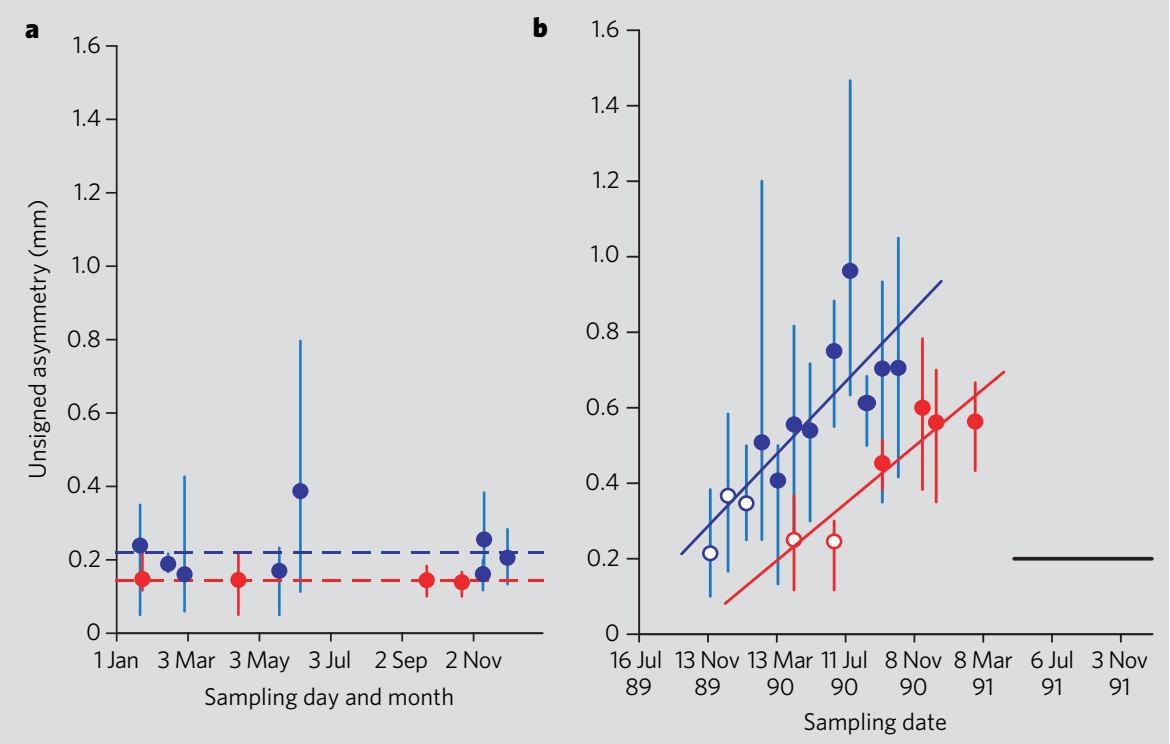

Figure 1 | Limb asymmetry in frog populations that soon declined, compared with non-declining 'control' populations. a, Asymmetry does not vary significantly among control samples of Litoria nannotis (blue) or L. genimaculata (red) (Kruskal-Wallis tests; $P>0.165$ ). Sampling years are pooled. Circles are sample means; error bars are ranges of individual values $(3 \leq n \leq 9)$. Dashed lines are pooled means. $b$, Asymmetry increases over time in pre-decline samples (symbols as in a). Filled circles are means that are significantly higher than the corresponding pooled controls (Mann-Whitney U-tests, Bonferronicorrected for multiple comparisons; $P<0.05$ ). Open circles are means that are not significantly higher than controls. Horizontal black bar indicates the time period of the local declines.
We found that asymmetry was greater in the pre-decline samples than in the controls (Fig. 1). It was not correlated with body size, which varied little. We found no directional asymmetry, and measurement error was small relative to unsigned asymmetry. At Paluma, the unsigned asymmetry increased over time,

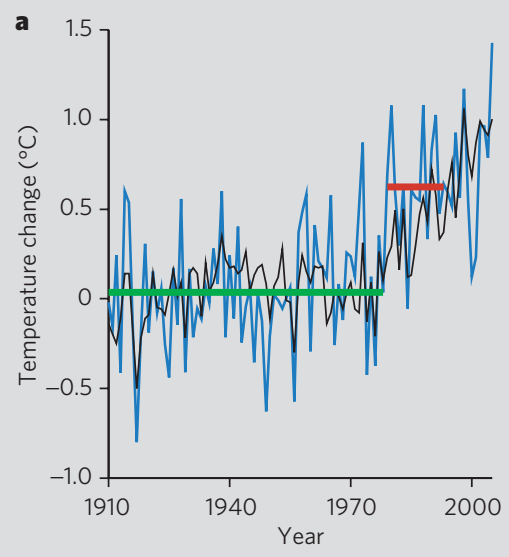

becoming significantly higher relative to the controls at 15-19 months before the declines. The frogs reach adult size in 1-2 years, so stress probably began to increase at least two years before these die-offs.

Irrespective of whether this increasing stress reflects disease or changes in the envi-

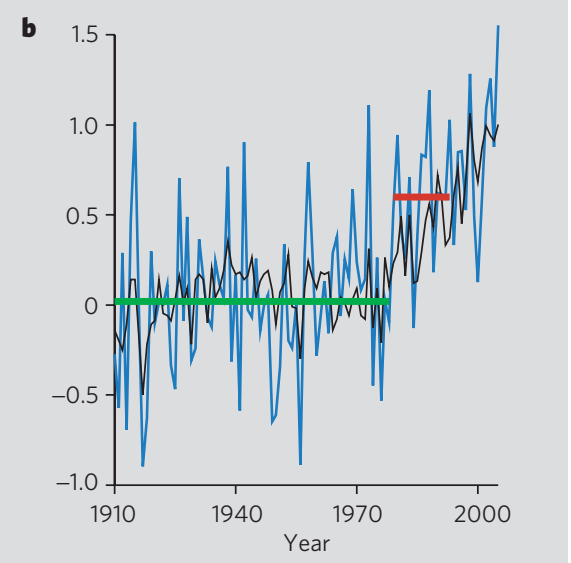

Figure 2 | Temperature changes and the period of major frog die-offs in Queensland,

Australia. Annual mean surface temperature for global land areas (black line) is correlated with the corresponding mean (blue line) for a, Australia, and $\mathbf{b}$, Queensland $(r \geq 0.71, P<0.0001)$. Values are departures from a baseline mean for 1910-39. For both regions, the mean for the period of die-offs (red bar) was about $0.6^{\circ} \mathrm{C}$ above the baseline, whereas the mean for previous years (green bar) was not significantly increased. During 1988-91, just before the declines at Paluma, the means for these regions were $0.82{ }^{\circ} \mathrm{C}$ for Australia and $0.65{ }^{\circ} \mathrm{C}$ for Queensland. Data are from the Australian Bureau of Meteorology; details are available from the authors. 
ronment, the chytrid was probably not the only agent involved. According to the extinction-wave hypothesis, which has long been controversial $^{10-12}$, this pathogen spreads gradually across large regions, causing population crashes within 4-6 months of invading a new site ${ }^{13,14}$. The association of die-offs with previous stress, however, runs counter to this model. It is possible that shifting conditions facilitated the chytrid's invasion, its irruption or its emergence from a saprophytic, quiescent or non-lethal parasitic state.

The data from Queensland cover too few independent die-offs to test for an association with climate change ${ }^{10}$, but the period of the major declines ${ }^{13,15}$ coincides with dramatic regional warming, which, on diverse spatial scales, mirrors the global trend (Fig. 2). It has been claimed ${ }^{15}$ that shifts in temperature or precipitation can be ruled out as factors in these losses, but this claim is undermined by the choice of variables, stations and seasonal timeframes used in that particular study. The patterns from the Australian tropics agree with the climate-linked epidemic hypothesis ${ }^{1,5,6,11}$.

Nevertheless, we question the analysis of Pounds et al., which so far provides the only geographically broad test of this idea. Contrary to their working model ${ }^{1}$, our Figs 1, 2 indicate that multiyear warm periods may be more important in amphibian declines than single warm years. By focusing on the latter, the authors' test could be inconclusive.

Ross A. Alford ${ }^{\star}$, Kay S. Bradfield ${ }^{\star} \uparrow$, Stephen J. Richards ${ }^{\star}+$

*School of Marine and Tropical Biology, James Cook University, Townsville, Queensland 4811, Australia

e-mail: ross.alford@jcu.edu.au

†Present address: Durell Wildlife Conservation

Trust, Les Augres Manor, Trinity, Jersey JE3 5BP, UK

Present address: South Australian Museum,

North Terrace, Adelaide, South Australia 5000,

Australia

Received 13 February; accepted 10 May 2007.
1. Pounds, J. A. et al. Nature 439, 161-167 (2006).

2. van Dongen, S. J. Evol. Biol. 19, 1727-1743 (2006)

3. Parris, M. J. \& Cornelius, T. O. Ecology $85,3385-3395$ (2004).

4. Söderman, F., van Dongen, S., Pakkasmaa, S. \& Merilä, J. Oecologia 151, 593-604 (2007).

5. Reading, C. J. Oecologia 151, 125-131 (2007)

6. Kiesecker, J. M., Blaustein, A. R. \& Belden, L. K. Nature 410, 681-684 (2001).

7. Burgin, S., Schell, C. B. \& Briggs, C. Acta Zool. Sinica 51, 344-348 (2005)

8. Richards, S. J. \& Alford, R. A. Aust. J. Zool. 53, 229-236 (2005).

9. Alford, R. A., Bradfield, K. \& Richards, S. in Declines and Disappearances of Australian Frogs (ed. Campbell, A.) 34-43 (Environment Australia, Canberra, 1999).

10. Alford, R. A. \& Richards, S. J. Conserv. Biol. 11, 1026-1029 (1997).

11. Bosch, J., Carrascal, L. M., Durán, L., Walker, S. \& Fisher, M C. Proc. R. Soc. B 274, 253-260 (2007).

12. Pounds, J. A., Carnaval, A. C., Puschendorf, R., Haddad, C. F. \& Masters, K. L. Science 314, 1541-1542 (2006).

13. Laurance, W. F., McDonald, K. R. \& Speare, R. Conserv. Biol. 10, 406-413 (1996)

14. Lips, K. R. et al. Proc. Natl Acad. Sci. USA 103, 3165-3170 (2006).

15. Laurance, W. F. Biol. Conserv. 77, 203-212 (1996)

Competing financial interests: declared none. doi: $10.1038 /$ nature05940 